\title{
Kinetic Study on Enzymatic Hydrolysis of Cellulose in an Open, Inhibition-Free System
}

Murali Anuganti ${ }^{1 \ddagger}$, Hailin Fu ${ }^{1 \ddagger}$, Stephen Ekatan ${ }^{2}$, Challa V. Kumar ${ }^{1 *}$, Yao Lin ${ }^{1,2 *}$

${ }^{1}$ Department of Chemistry, University of Connecticut, Storrs, CT 06269, United States

${ }^{2}$ Polymer Program, Institute of Material Sciences, University of Connecticut, Storrs, CT 06269, United States

KEYWORDS. Cellulase, model cellulose film, kinetic modeling, surface plasmon resonance, Langmuir-Michaelis-Menten 


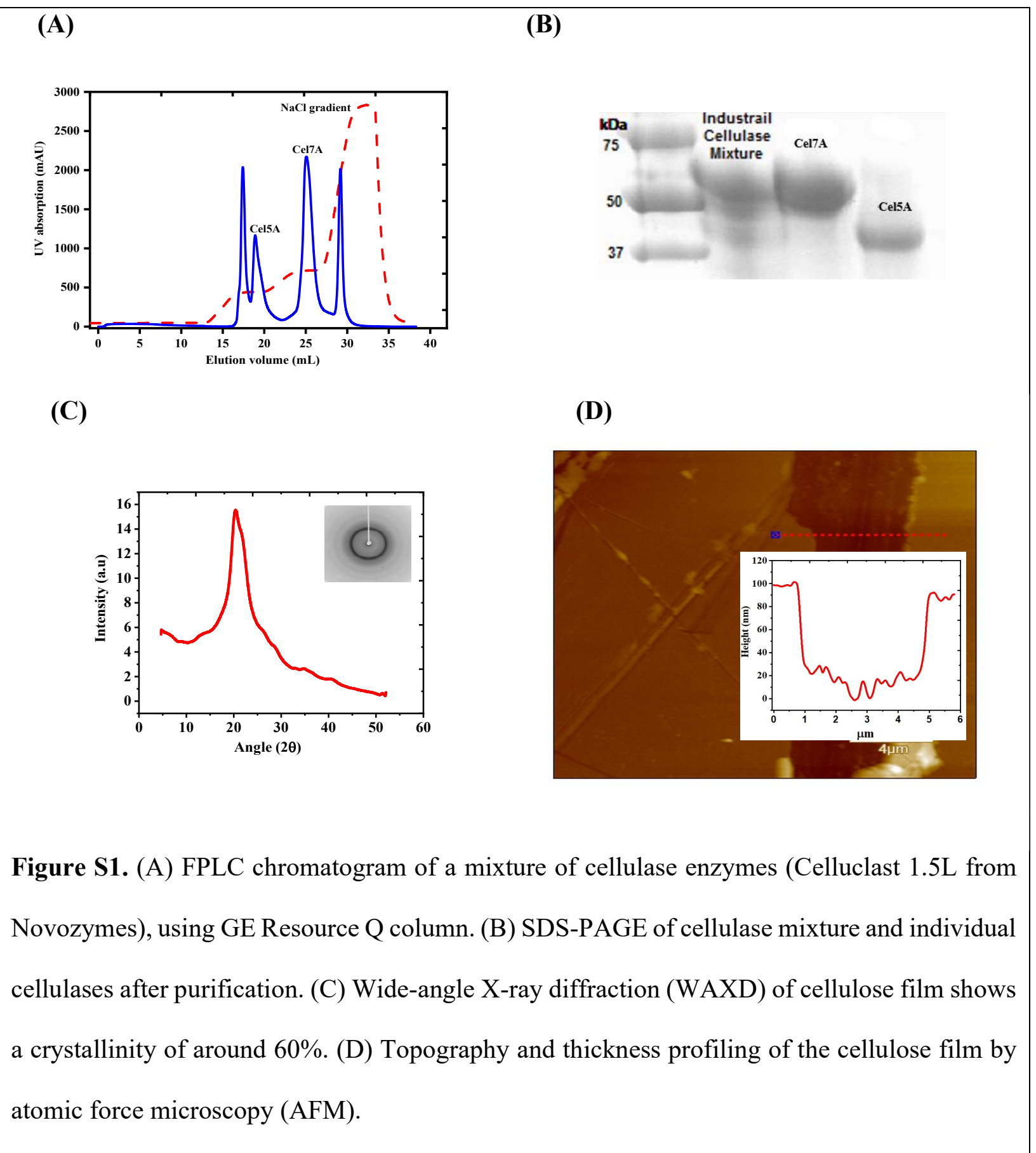




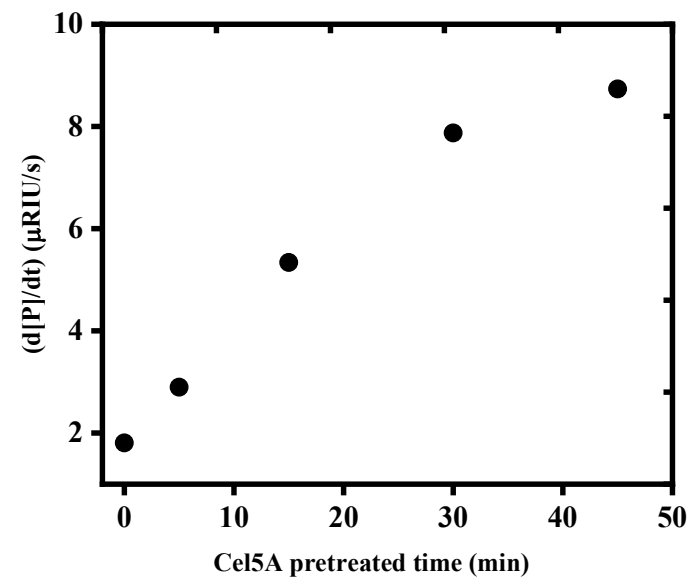

Figure S2. The effect of pretreatment of cellulose film by Cel5A on the pseudo-steady-state reaction rate of Cel7A at $40{ }^{\circ} \mathrm{C}$. 